\title{
Kindness Toward One's Self and Body: Exploring Mediational Pathways Between Early Memories and Disordered Eating
}

\author{
Cláudia Ferreira, $\mathrm{PhD}$ \\ Sara Oliveira, MSc \\ Ana Laura Mendes, MSc
}

CINEICC

University of Coimbra, Portugal

Correspondence concerning this article should be addressed to:

Ana Laura Mendes, University of Coimbra- Faculty of Psychology and Educational Sciences,

Rua do Colégio Novo, Apartado 6153, 3001-802. Coimbra (Portugal)

E-mail: analauramendes@live.com.pt

Phone: (+351)239851450; (+351)203851462 


\section{Abstract}

Recent literature has emphasized the role played by early emotional experiences on body image and eating-related psychopathology. Nevertheless, the mechanisms underlying the link between positive rearing experiences and eating psychopathology remain scarcely explored. Thus, this study aimed to explore a model in which it was hypothesized that early emotional experiences, characterized by warmth, safeness, and soothing, are negatively associated with disordered eating through higher levels of self-compassion and a more positive and caring relationship with one's own body. The study's sample comprised 490 women who completed an Internet based survey comprising self-report measures of interest.

Path analysis' results revealed that self-compassion and body appreciation fully mediated the impact of early positive emotional memories on eating psychopathology, when controlling the effect of age and Body Mass Index. The plausibility of the path model was confirmed which accounted for $49 \%$ of eating psychopathology's variance. Specifically, results demonstrated that $13 \%$ of self-compassion's variance was explained by positive early emotional memories. Also, early positive memories showed both direct and indirect (via selfcompassion) positive effects on body appreciation, accounting for $34 \%$ of its variance. Additionally, results revealed that positive early emotional experiences predicted lower levels of disordered eating, via higher levels of self-compassion and body appreciation.

By emphasizing the importance role of self-compassion and body appreciation against body image and eating psychopathology, the current study may offer important insights for future research and for the development of intervention programs.

\section{Keywords:}

Early emotional experiences; Self-compassion; Body appreciation; Disordered eating. 


\section{Introduction}

Several studies have highlighted that the quality of early care has a significant impact on later gene expression, brain maturation, and cognitive, emotional, and on the development of relational systems (e.g., Panksepp, 2010). Particularly, literature has reported the association between early emotional experiences, with parents and family members, and the adjustment of emotional regulation strategies (Gilbert \& Perris, 2000). It has been well documented that early interactions with attachment figures, which behave in a responsive, sensitive and available fashion, play a significant role in the promotion of an optimal development of the attachment system (Gerhardt, 2004; Irons, Gilbert, Baldwin, Baccus, \& Palmer, 2006). Embed in the affiliative-soothing system, feelings of security and connectedness are reported as fosterers of the ability to deal with challenging contexts and adversity (e.g., Gilbert, 2009). More specifically, early experiences involving warmth, reassuring, care, and affection responses have been related to subsequent well-being and resilience towards psychopathology (e.g., Gilbert, Baldwin, Irons, Baccus, \& Palmer, 2006). In contrast, when primary attachment figures are experienced as not being reliable, secure, or available, a sense of security cannot be attained, and thus defensive strategies may be activated (Gilbert, 2005; Brewin, Andrews, \& Gotlib, 1993; Cunha, Xavier, Martinho, \& Matos, 2014). Indeed, early negative experiences (i.e., characterized by rejection, over protection/control, or a lack of care) within the family have been linked with subsequent psychosocial difficulties and with several psychopathological indicators (e.g., Gilbert \& Perris, 2000).

Moreover, several accounts pointed out that rearing experiences can act as conditioned emotional memories (Gilbert \& Irons, 2009), which seem to have a crucial impact on emotional regulation (e.g., Matos \& Pinto-Gouveia, 2010). In fact, literature suggested that 
early negative relational experiences may operate as threat-activating memories and function like highly available emotional "hot spots" (Cheng \& Furnham, 2004). On the other hand, the evocation of rearing experiences seems to promote positive emotional states, and adaptive emotional resources such as self-compassion (e.g., Gilbert \& Irons, 2009; Richter, Gilbert, \& McEwan, 2009).

Self-compassion is a construct, rooted in the Buddhist philosophy, which can be defined as a set of three distinct abilities that mutually interact and enhance one another: (1) self-kindness - the ability to adopt an understanding and caring attitude towards the self, rather than being over-judgmental, in times of suffering; (2) common humanity - the recognition of one's experiences (such as personal setbacks or failures) as being part of the larger human experience, which promotes a sense of social connectedness, rather than of isolation; and (3) mindfulness - that implies a balanced awareness of the present moment experience, rather than avoidance or over-identification with such experiences, which permits a greater perspective towards unwanted or painful experiences (Neff, 2003a, 2003b). Regarding the benefits of cultivating a compassionate attitude towards oneself, selfcompassion has been seen as valuable when in one faces personal shortcomings and difficulties, and as being positively associated with positive affect, social connectedness, and adaptive coping (e.g., Gilbert, 2005; Neff, 2003a; Neff, 2009). Additionally, extensive data demonstrated that self-compassion can have an effective impact against negative affect and psychopathology (e.g., Ferreira, Matos, Duarte, \& Pinto-Gouveia, 2014; Neff, 2012; Raes, 2011).

Other relevant studies in the field of body image have documented the importance of nurturing a self-compassionate attitude. by reporting its significant association with lower body dissatisfaction, body shame and body surveillance, as well as with higher body image 
flexibility and body appreciation (Daye, Webb, \& Jafari, 2014; Ferreira, Pinto-Gouveia, \& Duarte, 2013; Ferreira et al., 2014; Kelly, Vimalakanthan, \& Miller, 2014; Wasylkiw, MacKinnon, \& MacLellan, 2012). Particularly, the significant association between selfcompassion and body appreciation has been corroborated by recent research (Homan \& Tylka, 2015; Kelly \& Stephen, 2016; Marta-Simões, Ferreira, \& Mendes, 2016).

Body appreciation is conceptualized as the ability to accept, respect and to be kind towards perceived defects in appearance and, at the same time, to recognize perceived body flaws as part of the common human experience (Avalos, Tylka \& Wood-Barcalow, 2005; Tylka \& Wood-Barcalow, 2015). Thus, body appreciation can be seen as the ability to adopt a compassionate and understanding attitude towards one's own body features and characteristics (Homan \& Tylka, 2015; Tylka \& Wood-Barcalow, 2015). Furthermore, body appreciation was found to be positively related to several adaptive emotional regulation and wellbeing indicators, such as optimism, proactive coping, positive affect, life satisfaction (Avalos et al., 2005; Tylka \& Kroon Vandiest, 2013; Wasylkiw et al., 2012), and favourable appearance evaluations, body esteem, and intuitive eating (Avalos et al., 2005; Tykla \& Kroon Van Diest, 2013). In contrast, body appreciation is negatively linked with body dissatisfaction, maladaptive body-related behaviours (such as body surveillance and body checking behaviours; Avalos et al., 2005; Tylka, 2013), and eating psychopathology (Tylka \& Kroon Van Diest, 2013).

Notwithstanding the fact that current approaches recommend a greater investment on adaptive and healthy emotional regulation processes, literature exploring the impact of relating positively with one's self and body image on eating psychopathology is still scarce (Smolak \& Cash, 2011). The current study aimed therefore to contribute to the clarification of the meaning of positive emotional regulation processes on disordered eating, by testing an 
integrative model that explores the impact of early memories of warmth and safeness on eating psychopathology, and whether self-compassion and body appreciation play a significant role on this association. It was hypothesized that of early positive affiliative experiences (with family figures) may be associated with lower severity of eating psychopathology's symptoms, when in the presence of higher levels of self-compassion and body appreciation.

\section{Materials and methods}

\section{Participants}

Four hundred and ninety women were collected from the Portuguese general population, with ages ranging from 18 to 54 years old $(M=24.76 ; S D=7.66)$. Participants presented a Body Mass Index (BMI) mean of 22.29 ( $S D=3.87$ ), which corresponds to normal weight values (WHO, 1995). Fifty-three (10.82\%) were underweight (BMI < 18.5), $349(71.22 \%)$ presented normal weight values $(18.5 \geq \mathrm{BMI} \leq 25.0)$, and $88(17.96 \%)$ were overweight $(\mathrm{BMI}$ > 25), which reflects the BMI distribution of the female Portuguese population (Poínhos et al., 2009).

\section{Measures}

Body Mass Index (BMI); BMI was calculated by computing the Quetelet Index, using information reported by the participants, namely self-reported height and weight $\left(\mathrm{Kg} / \mathrm{m}^{2}\right)$.

Early Memories of Warmth and Safeness Scale (EMWSS; Richter et al., 2009; Portuguese version by Matos, Pinto-Gouveia, \& Duarte, 2015); EMWSS is a self-report instrument, composed by 21 items, designed to measure early positive affiliate experiences. 
Participants are asked to indicate the frequency of warm, safe and affectionate emotional experiences which occurred in close relationships (e.g., "I felt that I was a cherished member of my family") during childhood. The response options are rated in a 5-point scale $(0=$ "No, never" to $4=$ "Yes, Most of the time"). This measure presented good psychometric properties, with a high level of internal consistency $(\alpha=.97)$, both for the original and the Portuguese versions.

Self-Compassion Scale (SCS; Neff, 2003a; Portuguese version by Costa, Marôco, Pinto-Gouveia, Ferreira, \& Castilho, 2015); this 26-item self-report measure assesses selfcompassion through two main components: a positive, which includes the dimensions selfkindness (e.g., "I'm tolerant of my own flaws and inadequacies"), common humanity (e.g., "I try to see my failings as part of the human condition") and mindfulness (e.g., "When I fail at something important to me I try to keep things in perspective"); and a negative one, comprising self-judgment, isolation and over-identification dimensions. The response options are rated on a Likert-type scale ranging from 1 ("almost never") to 5 (“almost always"). SCS presented good internal consistency in the original version $(\alpha=.92)$ and in the Portuguese version $(\alpha=.89)$. In the current study, the three positive dimensions were computed into one, and as a global measure of self-compassion.

Body Appreciation Scale (BAS-2; Tylka, Wood-Barcalow, 2015; Portuguese version by Marta-Simões, Mendes, Oliveira, Trindade, \& Ferreira, 2016); BAS-2 is a self-report instrument composed by 10 items that assesses the presence of respectful and accepting attitudes towards one's own body's features, regardless of its appearance (e.g., "I take a positive attitude towards my body"). The response options are rated on a 5-point Likert-type scale ( 1 = "never" to 5 = "always"). This instrument revealed a good internal consistency in 
the original version (with Cronbach's alpha values ranging from .93 to .97 in different samples; Tylka \& Wood-Barcalow, 2015) as well as in Portuguese version $(\alpha=.95)$.

Eating Disorder Examination Questionnaire (EDE-Q; Fairburn \& Beglin, 1994; Portuguese version by Machado et al., 2014); EDE-Q is a 36-item self-report measure, adapted from the Eating Disorder Examination Interview, which assesses the presence and severity of typical symptoms of eating psychopathology. It comprises four subscales: (1) restraint (e.g., "Have you tried to exclude from your diet any foods that you like in order to influence your shape or weight?”), (2) weight concern (e.g., "Have you felt fat?”), (3) shape concern (e.g., "How dissatisfied have you been with your shape?") and (4) eating concern (e.g., "Have you had a strong desire to lose weight?"). The items are rated for frequency of occurrence and for severity of key disordered eating attitudes and behaviours. The EDE-Q has been considered a gold standard measure of eating psychopathology in clinical and nonclinical populations. Furthermore, the EDE-Q has demonstrated the capacity to differentiate cases from non-cases of eating disorders, through the use of cut scores $\geq 4$. The EDE-Q showed high values of internal consistency, in both the original and the Portuguese versions ( $\alpha=.94$; Machado et al., 2014), with proved discriminant and concurrent validity, and testretest reliability (for a review see Fairburn, 2008).

Cronbach's alphas of these measures for the present study are reported in Table 1.

\section{Procedures}

The present study is part of a wider Portuguese project about the impact of different emotional regulation processes in psychological functioning and mental health. The sample was collected through online advertisements on social networks and all ethical requirements inherent to scientific research were respected. All participants were fully informed about the 
purpose and objectives of the study, the voluntary nature of their participation and the confidentiality of the data. Participants provided their written informed consent, before the completion of the battery of self-report questionnaires.

Initially self-report measures were completed by 514 participants of both genders (494 women and 20 men), with ages ranging from 17 to 57 years old. However, according to the purposes of this study, data was cleaned in order to exclude (i) male participants, and (ii) female participants who were younger than 18 years old and older than 54 years old.

\section{Data Analyses}

Data analyses were executed using the software IBM SPSS Statistics 22.0 (SPSS IBM; Chicago, IL) and path analyses with the software AMOS.

Descriptive statistics (means and standard deviations) were performed in order to examine the characteristics of the final sample. Furthermore, product-moment Pearson correlations analyses were used to explore the associations between BMI, age, early memories of warmth and safeness (EMWSS), self-compassion (SC), body appreciation (BAS-2) and eating psychopathology (EDE-Q). The magnitudes of these relationships were discussed taking into account Cohen's guidelines, in which correlations ranging between .1 and .3 are considered weak, moderate above .3 , and strong when equal to or superior than .5 , while considering a significance level of .05 (Cohen, Cohen, West, \& Aiken, 2003).

Finally, path analyses were conducted to estimate the presumed relations within the proposed model (Figure 1), specifically the mediator effects of self-compassion (SC) and body appreciation (BAS-2), in the relationship between early memories of warmth and safeness (EMWSS) and the engagement in disordered eating attitudes and behaviours (EDEQ). Therefore, early memories of warmth and safeness was considered as an exogenous 
variable, self-compassion and body appreciation were hypothesized as endogenous mediator variables, and eating psychopathology as an endogenous variable (Kline, 2005). The variables BMI and age were included in the path analysis model in order to control its effect. The Maximum Likelihood estimation method was used to test regression coefficients and to compute fit statistics. Additionally, a series of goodness-of-fit indices were selected to examine the adequacy of the overall model: the Normed Chi-square (CMIN/DF) which indicates a good fit when values are equal or below 3 (Kline, 2005); the Tucker Lewis Index (TLI) and the Comparative Fit Index (CFI), which both indicate the presence of an adequate model of which when within the range of .90 to .95 , and a very good fit with values above .95 (Brown, 2006). Additionally, the Root-Mean Square Error of Approximation (RMSEA) was examined, while considering that values between .05 and .08 indicate a good fit, and that when values bellow .05 indicate that a model presents a very good fit ( $p \leq .05$; Arbuckle, 2008). The significance of direct, indirect and total effects was assessed by Chi-square tests, and the significance of mediational paths was further examined through the Bootstrap resampling method, with 5000 Bootstrap samples and 95\% bias-corrected confidence intervals (CI). A significant mediation effect is denoted when zero is not included in the interval between the lower and the upper limits of the CI (Kline, 2005). Effects with $p<.050$ were considered statistically significant.

\section{Results}

\section{Preliminary data analyses}

The suitability of the current data for correlation analyses was examined. The analyses of Skewness and Kurtosis values seemed to confirm the assumption of normality of the distribution of the variables in study (Kline, 2005) 
Preliminary analyses indicated that data followed the assumptions of homoscedasticity, normality, linearity, independence of errors, and multicollinearity and singularity among the variables (Field, 2004).

\section{Descriptive and Correlation analyses}

The descriptive statistics for the study variables are presented on Table 1.

Correlations analysis' results showed that early memories of warmth and safeness were positively associated to self-compassion and body appreciation, with weak and moderate magnitudes, respectively. Furthermore, a negative and weak association was found between early memories of warmth and safeness and EDE-Q. Results, also, indicated that selfcompassion and body appreciation were positively associated with each other, and negatively correlated with EDE-Q.

Moreover, results showed that age revealed non-significant associations with body appreciation and with EDE-Q. Nonetheless, age presented positive correlations with BMI and self-compassion (SC), with moderate and weak magnitudes respectively. In contrast, a negative and weak relationship between age and early memories of warmth and safeness (EMWSS) was found. Finally, BMI presented negative associations with early memories of warmth and safeness and body appreciation, and a positive link to EDE-Q, with a moderate magnitude.

\section{Path Analysis}


The main goal of path analysis was to test whether the effects of early memories of warmth and safeness on eating psychopathology severity are carried through the mechanisms of self-compassion and body appreciation, while controlling the effects of BMI and age.

The path model was initially tested through a fully saturated model (i.e., with zero degrees of freedom), consisting of 27 parameters. However, analyses suggested the pertinence of the progressive removal of the following nonsignificant paths: the direct effect of early memories of warmth and safeness with family figures on EDE-Q ( $b_{\mathrm{EMwSS}}=.001 ; S E_{b}=.002$; $Z=.599 ; p=.549)$ and the direct effect of BMI on self-compassion $\left(b_{\mathrm{BMI}}=-0.16 ; S E_{b}=.008 ; Z\right.$ $=-1.947 ; p=.052$ ). These paths were eliminated and the model was readjusted (Figure 1). The final model revealed that all path coefficients were statistically significant $(p<.050)$, and presented an excellent model fit $\left[\chi^{2}(5)=13.012, p=.023, \mathrm{CMIN} / \mathrm{DF}=2.602\right.$; TLI $=.967$; CFI $=.989 ; \mathrm{RMSEA}=.057, p=.323 ; 95 \% \mathrm{CI}=.019$ to .096$]$.

More specifically, early memories of warmth and safeness had a direct effect of .32 $\left(\mathrm{b}_{\mathrm{EMwSS}}=.012 ; \mathrm{SE}_{\mathrm{b}}=.002 ; Z=7.459 ; p<.001\right)$ on self-compassion and of $.19\left(\mathrm{~b}_{\mathrm{EMwSS}}=\right.$ $\left..089 ; \mathrm{SE}_{\mathrm{b}}=.018 ; Z=4.981 ; p<.001\right)$ on body appreciation. It was also verified that selfcompassion directly predicted body appreciation $\left(\beta=.37 ; \mathrm{b}_{\mathrm{SC}}=4.528 ; \mathrm{SE}_{\mathrm{b}}=.468 ; Z=9.683\right.$; $p<.001)$. Finally, body appreciation presented a direct effect of $-.59\left(\mathrm{~b}_{\mathrm{BAS}-2}=-.090 ; \mathrm{SE}_{\mathrm{b}}=\right.$ $.005 ; Z=-17.119 ; p<.001)$ on EDE-Q.

The analysis of indirect effects showed that early memories of warmth and safeness presented an indirect effect on EDE-Q, of -.18 (95\% CI $=-.243$ to -.128$)$, which was totally carried by the effects of self-compassion and body appreciation. Also, results revealed that early positive memories with family figures had an indirect effect of $.12(95 \% \mathrm{CI}=.076$ to .164) on body appreciation, which was partially mediated by self-compassion. In turn, self- 
compassion revealed an indirect effect of $-.22(95 \% \mathrm{CI}=-.275$ to -.168$)$ on EDE-Q, which was totally explained by the effects of body appreciation.

Overall, the model accounted for $13 \%$ of self-compassion, $34 \%$ of body appreciation, and $49 \%$ of EDE-Q' variance, respectively. Furthermore, results revealed that the impact of early affiliative memories on disordered eating attitudes and behaviours is partially mediated by the effects of self-compassion and body appreciation. The tested model, with the standardized path coefficients and $R^{2}$ values, is presented in Figure 1.

\section{Figure 1 goes here}

\section{Discussion}

Literature has emphasized the association between early memories of warmth and safeness and adaptive emotional regulation processes and mental health (Richter et al., 2009). Also, several accounts have documented the crucial role of self-compassion against psychopathology (Neff, 2009; Raes, 2011), namely on body and eating-related psychopathology (Daye et al., 2014; Ferreira et al., 2014; Homan \& Tylka, 2015). Recently, Homan and Tylka (2015) highlighted self-compassion as a possible enhancer of body appreciation, by revealing its buffering effect on the negative effect of body image-related threats on body appreciation. Furthermore, empirical evidence has demonstrated that body appreciation is inversely associated with maladaptive eating, and positively linked to adaptive eating behaviours (Tylka \& Wood-Barcalow, 2015).

However, to the extent of our knowledge, this is the first study that examined the relationship between early positive memories, compassionate attitudes towards the self and one's body image, and disordered eating. More specifically, the current study presents an 
integrative model that explored the effect of early memories of warmth and safeness on eating psychopathology's severity, and the mediator role of self-compassion and body appreciation in this link.

According with the proposed hypotheses and with prior research (Richter et al., 2009), results of the correlation analysis demonstrated that early positive experiences were positively associated with adaptive emotion regulation processes (such as self-compassion towards the self), and negatively correlated with eating psychopathology's severity. These results are in line with theoretical and empirical evidences since they reveal that early positive emotional memories play a key role on the promotion of psychological adjustment (e.g., Gilbert \& Irons, 2009). Also, the present study adds to literature by revealing that these supportive early emotional experiences are positively linked with a compassionate attitude towards one's own body, regardless of its characteristics, and negatively associated with disordered eating behaviours and attitudes.

Path analysis's findings showed that the tested model revealed an excellent fit to the empirical data, accounting $49 \%$ of the variance of eating psychopathology severity. Also, this model demonstrated that $13 \%$ of self-compassion's variance was explained by positive early emotional experiences. Furthermore, results suggested that early positive memories had a positive direct effect on body appreciation, and an indirect effect, mediated by increased selfcompassion, explaining $34 \%$ of the variance of body appreciation. Additionally, results revealed that positive rearing experiences explained lower levels of disordered eating via higher levels of self-compassion and body appreciation, while controlling the effects of age and BMI. These findings seem to suggest that the relationship between early warmth and safeness memories and eating psychopathology's severity is complex, and influenced by different mechanisms. Indeed, path analysis' results indicated that, when controlling the effect 
of age and BMI, the impact of the evocation of positive early emotional memories on disordered eating is fully mediated by self-compassionate attitudes, and caring relationship with one's body.

Our results seem to support the conclusion that early positive experiences may promote an internal relationship based on an attitude of kindness, accepting and understanding. In turn, these positive emotional experiences and current self-compassionate attitudes seem be linked to a more adaptive and positive relation with one's own body, regardless of its characteristics, which may explain a lower tendency to adopt disordered eating attitudes and behaviours.

These novel findings cannot be considered without taking into account some limitations. Its cross-sectional design does not permit to infer conclusions regarding causality. Thus, upcoming studies should test the relationships between the study's variables in longitudinal or experimental design studies. Furthermore, our data may be constrained by limitations associated to the use self-report measures. However, some studies have shown that memories of early parenting are generally accurate, reliable, and stable over time, even in the face of considerable changes in mood and emotional states (Brewin et al., 1993; Cunha et al., 2014). Nevertheless, future studies should seek to replicate the present findings using other assessment methodologies, such as face-to-face interviews or observational instruments. Additionally, given that the sample of this study only comprised female participants, the generalization of results should be avoided. Although eating psychopathology is more prevalent in women, men also experience weight and body image-related difficulties and this study sample does not allow the generalization of obtained results. Therefore, upcoming research should investigate this model in male samples and explore gender differences. Besides, the use of a nonclinical sample impairs the generalization of the findings to clinical 
populations. Thus, in the future, studies should also investigate these in clinical samples. Finally, although the aim of the present study was to specifically address the mediator role of self-compassion and body appreciation, the complex nature of disordered eating presupposes the existence of different relevant variables in the association between emotional experiences of warmth and safeness and eating psychopathology's severity. In this line, future research should then expand on this model by testing different meditators emotional mechanisms.

In conclusion, our findings seem to support that women who present more early positive emotional experiences tend to cultivate a more kind and understanding relationship towards the self and one's own body, which seem to decrease the women engagement in disordered eating behaviours. In this line, our results seem to indicate that the impact of these early positive emotional experiences on eating disordered attitudes and behaviours may be highly dependent to the existence of the ability to develop self-compassionate attitudes.

The present study appears to offer a significant contribution to literature and clinical practice, by providing preliminary evidence for the relevance of targeting self-compassionate abilities within intervention programs for body image and eating-related difficulties.

\section{References}

Arbuckle, J. (2008). AMOS 17 Users' Guide. Chicago, IL: SPSS.

Avalos, L., Tylka, T., \& Wood-Barcalow, N. (2005). The Body Appreciation Scale: Development and psychometric evaluation. Body Image, 2, 285-297. doi:10.1016/j.bodyim.2005.06.002 
Brewin, C., Andrews, B., \& Gotlib, I. (1993). Psychopathology and early experience: A reappraisal of retrospective reports. Psychological Bulletin, 113, 82-98. doi: 10.1037/0033-2909.113.1.82

Brown, T. A. (2006). Confirmatory Factor Analysis for Applied Research. New York: Guilford Press.

Cheng, H., \& Furnham, A. (2004) Perceived parental rearing style, self-esteem and selfcriticism as predictors of happiness. Jounal of Happiness Studies, 5, 1-21. doi: 10.1023/B:JOHS.0000021704.35267.05

Cohen, J., Cohen, P., West, S. \& Aiken, L. (2003). Applied multiple regression/correlation analysis for the behavioural sciences (3th Ed.). New Jersey: Lawrence Erlbaum Associates.

Costa, J., Marôco, J., Pinto-Gouveia, J., Ferreira, C. \& Castilho, P. (2015). Validation of the Psychometric Properties of the Self-Compassion Scale. Testing the Factorial Validity and Factorial Invariance of the Measure among Borderline Personality Disorder, Anxiety Disorder, Eating Disorder and General Populations. Clinical Psychology and Psychotherapy. doi: 10.1002/cpp.1974

Cunha, M., Xavier, A., Martinho, M., \& Matos, M. (2014). Measuring Positive emotional memories in adolescents: psychometric properties and confirmatory factor analysis of the early memories of warmth and safeness scale. International Journal of Psychology and Psychological Therapy, 14(2), 245-259. Retrieved from: http://www.ijpsy.com/volumen14/num2/386/measuring-positive-emotional-memoriesin-EN.pdf

Daye, C., Webb, J., \& Jafari, N. (2014). Exploring self-compassion as a refuge against recalling the body-related shaming of caregiver eating messages on dimensions of 
objectified body consciousness in college women. Body Image, 11, 547-556. doi: 10.1016/j.bodyim.2014.08.001

Fairburn, C. (2008). Cognitive behavior therapy and eating disorders. New York: Guilford Press.

Fairburn, C., \& Beglin, S. (1994). Assessment of eating disorders: Interview of self-report questionnaire? International Journal of Eating Disorders, 16, 363-370. doi: $10.1002 / 1098-108 X(199412)$

Ferreira, C., Pinto-Gouveia, J., \& Duarte, C. (2013). Self-compassion in the face of shame and body image dissatisfaction: Implications for eating disorders. Eating Behaviors, 14(2), 207 - 210. doi: 10.1016/j.eatbeh.2013.01.005.

Ferreira, C., Matos, M., Duarte, C., \& Pinto-Gouveia, J. (2014). Shame memories and eating psychopathology: The buffering effect of self-compassion. European Eating Disorders Review, 22, 487-494. doi: 10.1002/erv.2322

Field, A. (2004). Discovering statistics using SPSS (3th Ed.). London: Sage Publications

Gerhardt, S. (2004). Why Love Matters. How Affection Shapes a Baby's Brain. London: Bruner-Routledge.

Gilbert, P. (2005). Social mentalities: A biopsychosocial and evolutionary reflection on social relationships. In M. Baldwin (Ed.), Interpersonal cognition (pp. 299-335). New York: Guilford.

Gilbert, P. (2009). The compassionate mind: A new approach to life's challenges. London, Constable-Robinson.

Gilbert, P., Baldwin, M., Irons, C., Baccus, J., \& Palmer, M. (2006). Self-criticism and selfwarmth: An imagery study exploring their relation to depression. Journal of Cognitive Psychotherapy, 20, 183-200. doi:10.1891/088983906780639817 
Gilbert, P., \& Irons, C. (2009). Shame, self-criticism, and self-compassion in adolescence. In N Allen (Ed.). Psychopathology in Adolescence. Cambridge: Cambridge University Press.

Gilbert, P., \& Perris, C. (2000). Early experiences and subsequent psychosocial adaptation: An introduction. Clinical Psychology and Psychotherapy, 7, 243-245. doi:10.1002/1099-0879(200010)7:4<243::AID-CPP254>3.0.CO;2-H

Homan, K., \& Tylka, T. (2015). Self-compassion moderates body comparison and appearance self-worth's inverse relationships with body appreciation. Body Image, 15, 1-7. doi: 10.1016/j.bodyim.2015.04.007

Irons, C., Gilbert, P., Baldwin, M. W., Baccus, J. R., \& Palmer, M. (2006). Parental recall, attachment relating and self-attacking/self-reassurance: their relationship with depression. British Journal of Clinical Psychology, 45(3), 297-308. doi: $10.1348 / 014466505 \times 68230$

Kelly, A. C., \& Stephen, E. (2016). A daily diary study of self-compassion, body image, and eating behavior in female college students. Body Image, 17, 152-160. doi: 10.1016/j.bodyim.2016.03.006.

Kelly, A., Vimalakanthan, K., \& Miller, K. (2014). Self-compassion moderates the relationship between body mass index and both eating disorder pathology and body image flexibility. Body Image, 11, 446-453. doi: 10.1016/ j.bodyim.2014.07.005

Kline, R. (2005). Principles and Practice of Structural Equation Modelling (2nd Ed.) New York: The Guildford Press.

Machado, P., Martins, C., Vaz, A., Conceição, E., Bastos, A., \& Gonçalves, S. (2014). Eating disorder Examination questionnaire: psychometric properties and norms for the 
Portuguese population. European Eating Disorders Review, 22, 448-453. doi: 10.1002/erv.2318

Marta-Simões, J., Ferreira, C., \& Mendes, L. (2016). Exploring the effect of external shame on body appreciation among Portuguese young adults: The role of self-compassion. Eating Behaviors, 23. doi: 10.1016/j.eatbeh.2016.10.006

Marta-Simões, J., Mendes, L., Oliveira, S., Trindade, I., \& Ferreira, C. (2016, May). Validation of the Body Appreciation Scale-2 for the Portuguese population. Paper presented at the3rd IPLeiria International Health Congress, Leiria, Portugal.

Matos, M., \& Pinto-Gouveia, J. (2010). Shame as a traumatic memory. Clinical Psychology and Psychotherapy, 17, 299-312. doi: 10.1002/cpp.659

Matos, M., Pinto-Gouveia, J., \& Duarte, C. (2015). Psychometric properties of the Portuguese version of the Early Memories of Warmth and Safeness Scale. Manuscript in Preparation.

Neff, K. (2003a). Development and validation of a scale to measure self-compassion. Self and Identity, 2, 223-250. doi: 10.1080/15298860390209035

Neff, K. (2003b). Self-compassion: An alternative conceptualization of a healthy attitude toward oneself. Self and Identity, 2, 85-102. doi: 10.1080/15298860390129863

Neff, K. (2009). Self-compassion. In M. Leary \& R. Hoyle (Eds.), Handbook of individual differences in social behavior (pp. 561-573). New York: Guilford Press.

Neff, K. (2012). The science of self-compassion. In C. Germer \& R. Siegel (Eds.), Compassion and Wisdom in Psychotherapy (pp. 79-92). New York: Guilford Press.

Panksepp, J. (2010). Affective neuroscience of the emotional Brain Mind: evolutionary perspectives and implications for understanding depression. Dialogues in Clinical NeuroSciences, 12, 533 -545. doi: 10.1016/S0140-6736(10)62052-1 
Poínhos, R., Franchini, B., Afonso, C. et al. (2009) Alimentação e estilos de vida da população Portuguesa: Metodologia e resultados preliminares [Alimentation and life styles of the portuguese population: Methodology and preliminary results]. Alimentação Humana 15(3), 43-60. Retrieved from: http://www.alimentacaosaudavel.dgs.pt/activeapp/wpcontent/files_mf/1445339604alimenta\%C3\%A7\%C3\%A3oeestilosdevidadapopul $\% \mathrm{C} 3 \% \mathrm{~A} 7 \% \mathrm{C} 3 \% \mathrm{~A} 3$ oportuguesa.pdf

Raes, F. (2011). The effect of self-compassion on the development of depression symptoms in a nonclinical sample. Mindfulness, 2, 33-36. doi: 10.1007/s12671-011-0040-y

Richter, A., Gilbert, P., \& McEwan, K. (2009). Development of an early memories of warmth and safeness scale and its relationship to psychopathology. Psychology and Psychotherapy: Theory, Research and Practice, 82, 171-184. doi: $10.1348 / 147608308 X 395213$

Smolak, L., \& Cash, T. F. (2011). Future challenges for body image science, practice, and prevention. In T. F. Cash, \& L. Smolak (Eds.), Body image: A handbook of science, practice, and prevention (pp. 471-478) (2nd Ed ). New York: Guilford Press.

Tylka, T. (2013). Evidence for the Body Appreciation Scale's measurememnt equivalence/invariance between U.S. college women and men. Body Image, 10, 415418. doi: 10.1016/j.bodyim.2013.02.006

Tylka, T., \& Kroon Van Diest, A. (2013). The Intuitive Eating Scale-2: Item refinement and psychometric evaluation with college women and men. Journal of Counseling Psychology, 60, 137-153. doi: 10.1037/a0030893 
Tylka, T., \& Wood-Barcalow, N. (2015). The Body Appreciation Scale-2: Item refinement and psychometric evaluation. Body Image, 12, 53-67. doi:10.1016/j.bodyim.2014.09.006

Wasylkiw, L., MacKinnon, A., \& MacLellan, A. (2012). Exploring the link between selfcompassion and body image in university women. Body Image, 9, 236-245. doi: 10.1016/j.bodyim.2012.01.007

WHO (1995). Physical status: the use and interpretation of anthropometry. Reports of a WHO Expert Committee. WHO Technical Report series 854. Geneva: World Health Organization 
Table 1

Means (M), standard deviations (SD), Cronbach alphas and Intercorrelation scores on self-report measures $(N=490)$

\begin{tabular}{|c|c|c|c|c|c|c|c|c|c|c|c|c|}
\hline Measures & $M$ & $S D$ & $\alpha$ & 1. & 2. & 3. & 4. & 5. & 6. & 7. & 8. & 9 \\
\hline 1. Age & 22.29 & 3.87 & - & 1 & - & - & - & - & - & - & - & - \\
\hline 2. BMI & 24.76 & 7.66 & - & $.42 * * *$ & 1 & - & - & - & - & - & - & - \\
\hline 3.EMWSS & 62.58 & 17.64 & .98 & $-.14 * * *$ & $-.14 * * *$ & 1 & - & - & - & - & - & - \\
\hline 4.SC & 3.14 & .67 & .91 & $.16^{* * *}$ & -.03 & $.29 * * *$ & 1 & - & - & - & - & - \\
\hline 5.BAS-2 & 36.45 & 8.23 & .95 & -.05 & $-.37 * * *$ & $.34 * * *$ & $.43^{* * *}$ & 1 & - & - & - & - \\
\hline 6.EDE-Q_total & 1.35 & 1.25 & .95 & .08 & $.44 * * *$ & $-.20 * * *$ & $-.22 * * *$ & $-.67 * * *$ & 1 & - & - & - \\
\hline 7.EDE-Q_rest & 1.10 & 1.31 & .80 & $.09 *$ & $.29 * * *$ & -.08 & -.08 & $-.35 * * *$ & $.76^{* * *}$ & 1 & - & - \\
\hline 8.EDE-Q_ec & .66 & 1.08 & .85 & .02 & $.28 * * *$ & $-.19 * * *$ & $-.17 * * *$ & $-.54 * * *$ & $.86^{* * *}$ & $.59 * * *$ & 1 & - \\
\hline 9.EDE-Q_wc & 1.62 & 1.49 & .83 & .07 & $.47 * * *$ & $-.21 * * *$ & $-.24 * * *$ & $-.68 * * *$ & $.94 * * *$ & $.61 * * *$ & $.77 * * *$ & 1 \\
\hline 10.EDE-Q_sc & 1.77 & 1.59 & .92 & $.09 *$ & $.45^{* * *}$ & $-.22 * * *$ & $-.24 * * *$ & $-.72 * * *$ & $.96^{* * *}$ & $.60 * * *$ & $.77 * * *$ & $91 * * *$ \\
\hline
\end{tabular}

Note : BMI = Body Mass Index EMWSS = Early Memories of Warmth and Safeness Scale; SC = Self-Compassion dimension of SCS; BAS-2 = Body Appreciation Scale; EDE-Q_total= Global score of Eating Disorder Examination Questionnaire; EDE-Q_rest = Restraint subscale of EDE-Q; EDEQ_ec = Eating concern subscale of EDE-Q; EDE-Q_wc = Weight concern subscale of EDE-Q; EDE-Q_sc = Shape concern subscale of EDE-Q;

$* * * p<.001$ 


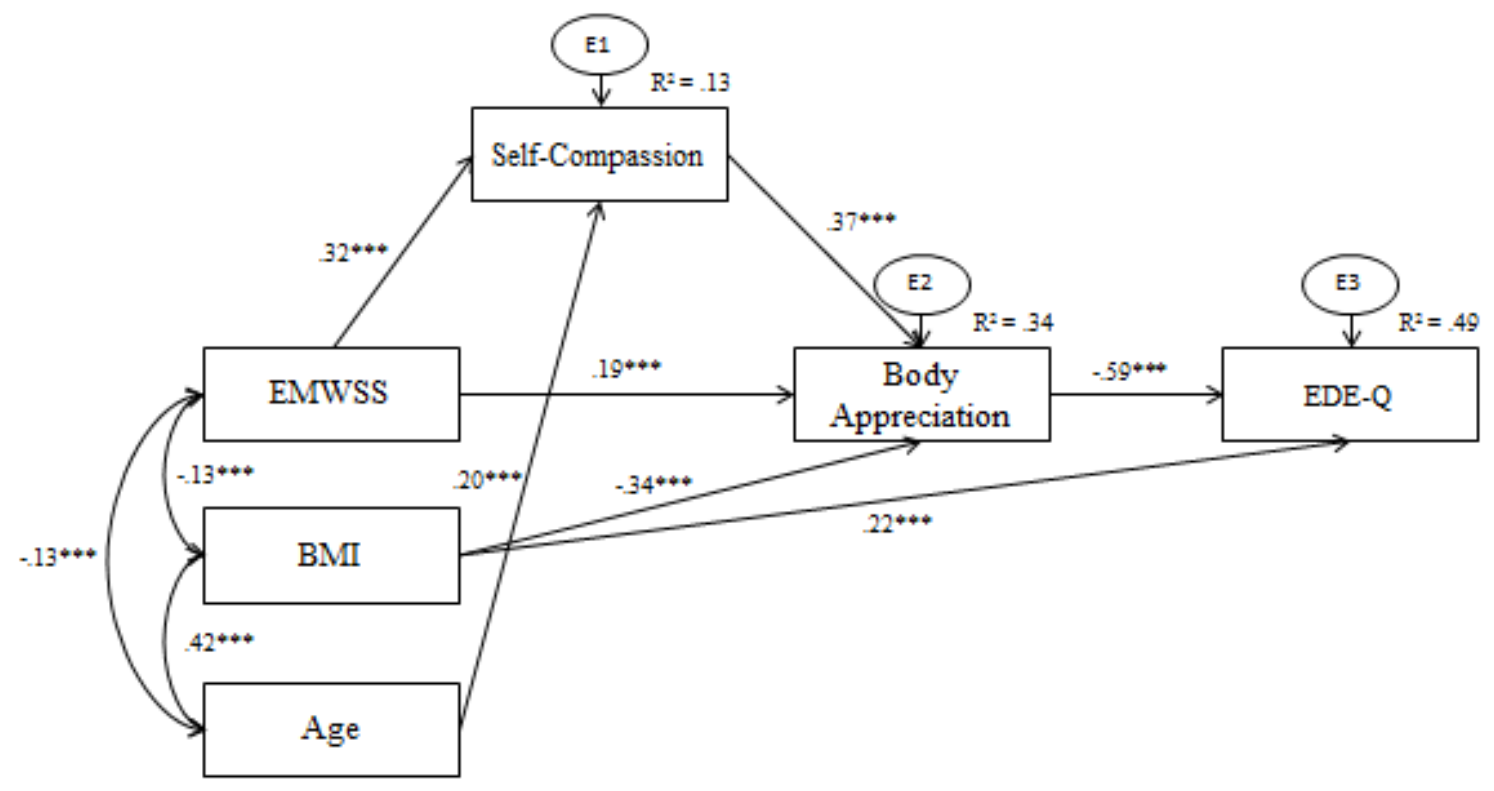

Figure 1. Final path model.

Note. ${ }^{* * *} p<.001$; EMWSS $=$ Early Memories of Warmth and Safeness Scale; BMI = Body Mass Index; EDE$\mathrm{Q}=$ Eating Disorder Examination Questionnaire 